Purdue University

Purdue e-Pubs

2014

Local Measurement of Flow Boiling Heat Transfer in an Array of Non-Uniformly Heated Microchannels

S. N. Ritchey

Purdue University

J.A. Weibel

Purdue University

S V. Garimella

Purdue University, sureshg@purdue.edu

Follow this and additional works at: http://docs.lib.purdue.edu/coolingpubs

Ritchey, S. N.; Weibel, J. A.; and Garimella, S V., "Local Measurement of Flow Boiling Heat Transfer in an Array of Non-Uniformly Heated Microchannels" (2014). CTRC Research Publications. Paper 206.

http://dx.doi.org/http://dx.doi.org/10.1016/j.ijheatmasstransfer.2013.12.012

This document has been made available through Purdue e-Pubs, a service of the Purdue University Libraries. Please contact epubs@purdue.edu for additional information. 


\title{
Local Measurement of Flow Boiling Heat Transfer in an Array of Non-Uniformly Heated Microchannels
}

\author{
Susan N. Ritchey, Justin A. Weibel, Suresh V. Garimella* \\ Cooling Technologies Research Center, an NSF I/UCRC \\ School of Mechanical Engineering, Purdue University \\ 585 Purdue Mall \\ West Lafayette, IN USA 47907
}

${ }^{*}$ Corresponding author. Tel: +17654945621
E-mail address: sureshg@ purdue.edu (S.V. Garimella). 


\begin{abstract}
As electronics packages become increasingly thinner and more compact due to size, weight, and performance demands, the use of large intermediate heat spreaders to mitigate heat generation nonuniformities are no longer a viable option. Instead, non-uniform heat flux profiles produced from chipscale variations or from multiple discrete devices are experienced directly by the ultimate heat sink. In order to address these thermal packaging trends, a better understanding of the impacts of non-uniform heating on two-phase flow characteristics and thermal performance limits for microchannel heat sinks is needed. An experimental investigation is performed to explore flow boiling phenomena in a microchannel heat sink with hotspots, as well as non-uniform streamwise and transverse peak-heating conditions spanning across the entire heat sink area. The investigation is conducted using a silicon microchannel heat sink with a $5 \times 5$ array of individually controllable heaters attached to a $12.7 \mathrm{~mm} \times 12.7 \mathrm{~mm}$ square base. The channels are $240 \mu \mathrm{m}$ wide, $370 \mu \mathrm{m}$ deep, and separated by $110 \mu \mathrm{m}$ wide fins. The working fluid is the dielectric fluorinert liquid FC-77, flowing at a mass flux of approximately $890 \mathrm{~kg} / \mathrm{m}^{2} \mathrm{~s}$. High-speed visualizations of the flow are recorded to observe the local flow regimes. Despite the substrate beneath the microchannels being very thin $(200 \mu \mathrm{m})$, significant lateral conduction occurs and must be accounted for in the calculation of the local heat flux imposed. For non-uniform heat input profiles, with peak heat fluxes along the streamwise and transverse directions, it is found that the local flow regimes, heat transfer coefficients, and wall temperatures deviate significantly from a uniformly heated case. These trends are assessed as a function of an increase in the relative magnitude of the nonuniformity between the peak and background heat fluxes.
\end{abstract}

Keywords: non-uniform heating, hot spot, microchannel heat sink, two-phase flow, boiling

\title{
1. Introduction
}

Many studies in the literature have investigated uniform base heating profiles applied to microchannel heat sinks, as reviewed, for example, in [1-3]. These studies experimentally measured the onset of nucleate boiling [4], pressure drop [5,6], and heat transfer coefficient [5,7,8], and also developed models to predict the critical heat flux (CHF) $[9,10]$. In addition, flow regime maps have been developed under a variety of operating conditions $[11,12]$. While these studies have provided a thorough understanding of microchannel flow boiling under ideal heating conditions, realistic applications may impose highly nonuniform heat fluxes due to chip- and system-level variations [13]. In order to reliably predict the performance in actual applications, a better understanding of two-phase microchannel cooling under nonuniform heating conditions is needed, especially in terms of deviations in heat transfer performance and flow behavior compared to uniform heating conditions. 
A discretized theoretical model for assessment of non-uniform heating in microchannels was developed by Koo et al. [14] using correlations for flow boiling heat transfer and pressure drop. The model was used to explore optimal geometric designs, but was limited in its ability to assess lateral flow instabilities across channels and for CHF prediction. A numerical model developed by Sarangi et al. [15] predicted the pressure drop and thermal resistance of a uniformly heated microchannel, and location of boiling incipience. The model was extended to include non-uniform heating, which showed a large impact on the overall fluid dynamics and heat transfer of the system. Revellin and Thome [9] developed a onedimensional theoretical model to predict CHF in microchannels under uniform heating conditions, which was further modified by Revellin et al. [16] to incorporate non-uniform axial heat fluxes.

Past experimental efforts have studied the effects of non-uniform microchannel heating on flow boiling instabilities [17], pressure drop, and maximum wall temperatures [18-20]. It was found that hotspots near the inlet created a large transverse temperature variation across the heat sink due to nonuniform fluid distribution. Maldistribution was caused by a local increase in two-phase pressure drop due to boiling, which diverted single-phase liquid to other locations; this effect was most pronounced for a hot spot at the inlet. Transient non-uniform heating situations have also been investigated [19,21].

Prior experimental studies with non-uniform heating conditions have typically focused on single point hotspots. The effect of location and configuration of the hotspot as well as that of multiple hotspots on thermal performance has not been fully explored. In addition, a rigorous study of other heating profiles, especially superposed on a uniform background heat flux as would be realized in application, has not been reported. The present work studies both local hotspots and increasingly non-uniform peak-heating profiles across the heat sink, both in the flow direction and perpendicular to it, with respect to thermal performance and flow boiling phenomena. This work considers the effects of non-uniform heating on the local heat transfer coefficients, wall temperatures, heat fluxes, and boiling characteristics of a microchannel heat sink. Concentration of the heat input typically results in higher local heat transfer coefficients due to transition into the more efficient boiling regime at the expense of increased local wall temperatures. This work enables better assessment of existing heat transfer models for prediction of nonuniform heating profiles.

\section{Experimental Methods}

\subsection{Test Section}

The microchannel test section used in the current study was described in detail by Harirchian and Garimella [12]; it was modified for the purposes of the current study and is shown in Figure 1a. A transparent, polycarbonate manifold cover plate seals and routes the working fluid through a silicon microchannel heat sink with a base area of $12.7 \mathrm{~mm} \times 12.7 \mathrm{~mm}$. The total silicon thickness is 
approximately $650 \mu \mathrm{m}$. The heat sink is mounted on a printed circuit board that is offset from an electrical quick-connect board with an insulating G10 glass-epoxy composite layer. An insulating $0.4 \mathrm{~mm}$ thick borosilicate glass sheet is sandwiched between the microchannel heat sink and cover plate to protect the polycarbonate (rated to a temperature of $115-130{ }^{\circ} \mathrm{C}$ ), and forms the rigid top wall of the microchannels. The fluid enters the channels through an inlet header section with a flow length of $10 \mathrm{~mm}$, width of 12.7 $\mathrm{mm}$, and a height equal to that of the heat sink plus borosilicate glass thickness.

Parallel microchannels are cut into the top surface of the silicon chip using a dicing saw, and are shown in Figure 1b. A single heat sink with 35 microchannels was used for the current study $(240 \mu \mathrm{m}$ channel width, $370 \mu \mathrm{m}$ channel depth, and $110 \mu \mathrm{m}$ fin width). Each channel was cut with a number of

passes, which created some waviness on the bottom surface. The average channel bottom roughness in the region of a single cut is $0.2 \mu \mathrm{m}$, and the overall average surface roughness of the bottom and sides of the channels are $0.82 \mu \mathrm{m}$ and $0.1 \mu \mathrm{m}$, respectively.

A $5 \times 5$ array of resistance heaters and temperature-sensing diodes is fabricated on the bottom side of the heat sink, as shown in Figure 1b. Since the individual heater resistances are nearly identical, a single voltage can be applied across multiple heaters in parallel to provide a uniform flux over a desired area. Up to two DC voltage power supplies are connected to provide the customized, non-uniform heat flux profiles applied to the underside of the microchannels investigated in the current study. The heat generated and local temperature at each element are calculated based on the calibrated heater/sensor resistance and the applied voltage. The relationship between the voltage and temperature of each sensor is calibrated in a convection oven. More details about the calibration procedure for each element can be found in [6].

\subsection{Flow Loop}

The experimental flow loop used is the same as that described by Harirchian and Garimella [12], and a schematic diagram is shown in Figure 2. The dielectric fluid FC-77 is circulated through the flow loop using a Micropump 415A magnetically coupled gear pump. A preheater sets the fluid to the desired inlet temperature upstream of the test section. Downstream of the test section, a liquid-to-air heat exchanger cools the fluid back to room temperature before it enters the reservoir. A McMillan Flo-114 liquid flow meter, with a range of 20-200 $\mathrm{mL} / \mathrm{min}$, measures the liquid flow rate through the loop. T-type thermocouples are located upstream of the preheater, upstream and downstream of the test section, and downstream of the heat exchanger. A 2200 series Omega differential pressure transducer measures the pressure drop across the test section.

High-speed visualization is performed with a Photron Fastcam Ultima APX high-speed digital video camera and a Nikon ED 200 mm lens. A Sunoptics Titan 300 xenon arc lamp is used for inline 
illumination of the test chip for the visualizations. Images are extracted from high-speed videos captured at 6,000 frames per second with a shutter speed of $6 \mathrm{kHz}$.

\subsection{Test Procedure}

Before running a test, the liquid is degassed using an expandable reservoir and a vacuum pump. The degassing procedure and the design of the expandable reservoir are adapted from [22]. The test fluid, FC77 , contains $41 \%$ air by volume, or 283 ppm, at ambient temperature and pressure. An expandable container with a locking mechanism allows expansion and contraction of the reservoir to control the system pressure. First, the reservoir is expanded to create a gas space at the top of the reservoir. A vacuum pump connected to the top of the reservoir lid is turned on for 5 minutes to remove air and the FC-77 vapor that has collected in the gas space. The reservoir is left expanded and at a vacuum pressure for one hour to allow air to diffuse from the liquid into the gas space. The process is repeated until the pressure in the reservoir remains constant with time, indicating that air is not actively dissolving out of the liquid in the reservoir. The fluid is cycled through the loop and the reservoir degassing process is repeated several times. To ensure the fluid is fully degassed, the system is set to atmospheric pressure, fluid is pumped through the loop, and the preheater is used to boil the fluid. The measured preheater fluid temperature at incipience is confirmed to be the saturation temperature of FC-77 $\left(97^{\circ} \mathrm{C}\right)$.

Experiments are conducted at a single mass flux of $890 \mathrm{~kg} / \mathrm{m}^{2} \mathrm{~s}$. Fluid is pumped through the loop at a constant flow rate and preheated to approximately $91{ }^{\circ} \mathrm{C}$, which corresponds to a subcooling of $6{ }^{\circ} \mathrm{C}$ at the inlet to the heat sink. The flow rate and inlet temperature are maintained at constant values throughout the test. The expandable reservoir is used to set the system at atmospheric pressure prior to turning on the heater elements. During testing, the system pressure increases slightly due to the bulk temperature rise of the fluid; however, this increase is minor $(12.4 \mathrm{kPa})$, and smaller than is practically correctable with the expandable reservoir system.

\subsection{Test Cases}

A variety of heating cases were investigated as summarized in Figure 3. The heat transfer coefficients, wall temperatures, fluid temperatures, and the locations of boiling via high-speed imaging are obtained for each case.

The first cases (Figure 3) correspond to hotspots that span either the width or length of the microchannel heat sink in transverse and streamwise directions: singular central transverse (1a), central streamwise (1b), inlet transverse (1c), and two transverse hotspots (1d) at the inlet and outlet. The hotpot heater locations are turned on (shown in red) while the rest are powered off (shown in gray). For these hotspot heating cases, the heat supplied to the strips of active heaters is incremented from zero until the 
maximum heat flux for the test is reached. The maximum heat flux limit is reached when the wall temperature reaches $140{ }^{\circ} \mathrm{C}$, to prevent the solder bumps in the test chip from degrading.

The second set of test cases consider a non-uniform heating condition where a peak heat input is imposed along the width and length of the microchannel in the transverse (2a) and streamwise (2b) directions. In these latter two non-uniform heating cases, the total power input to the chip remains constant, but the local power input distribution is adjusted to increase the disparity between the peak and background heat fluxes. The total constant power input in this second set of cases is the same as the maximum power input for the corresponding hotspot heating cases.

\section{Data Reduction}

The data reduction method is described in Harirchian and Garimella [6]. Key modifications to this process take into account the enhanced substrate spreading that occurs for non-uniform heating profiles. Pressure-dependent local fluid properties and saturation temperatures are accounted for in the data reduction procedure to account for variations along the flow length.

The local heat transfer rate from the microchannels to the fluid, $\dot{q}_{n e t}$, is calculated based on an energy balance for each heating element as

$$
\dot{q}_{n e t, i j}=\dot{q}_{g e n, i j}-\dot{q}_{l o s s, i j}-\dot{q}_{c o n d, i j}
$$

The energy generated by the heating elements is denoted as $\dot{q}_{g e n}$ and is calculated as $\dot{q}_{g e n}=V^{2} / R$. The heat loss from each heating element is by natural convection to the ambient air, radiation to the surroundings, and conduction from the microchannel heat sink to the cover plate and circuit board. A relationship between the base temperature and heat loss is experimentally obtained via measuring the amount of heat input that can be sustained before the test section is charged with coolant. A complete description of the procedure used to obtain the heat loss for each sensor is found in [23]. The energy conducted laterally from one heating element to the next is denoted as $\dot{q}_{c o n d}$. When non-uniform heating profiles are imposed, there is significant lateral conduction of heat through the silicon heat sink. Heat conduction between elements is calculated as

$$
\dot{q}_{c o n d, i j}=k_{S i} \frac{L}{5}(t-d) \frac{\left(4 T_{i, j}-T_{i+1, j}-T_{i-1, j}-T_{i, j+1}-T_{i, j-1}\right)}{L / 5},
$$

where the total net conduction is dependent on the four neighboring elements to heater $i, j$.

During single-phase flow, the bulk fluid temperature above each heating element is calculated as

$$
T_{f, i j}=T_{i n}+\frac{\sum_{i} \dot{q}_{n e t, i j}}{G w d N / 5 c_{p}},
$$


where $\sum_{i} \dot{q}_{n e t, i j}$ is the sum of the net heat transfer to the fluid from the inlet to the heating element in question. The fluid temperature rise is based on the available sensible heat up until the saturation temperature is reached, at which point the fluid temperature is set equal to the saturation temperature.

The local wall temperature is corrected from the measured diode temperature by accounting for conduction from the substrate to the base of the microchannel, calculated as

$$
T_{w, i j}=T_{d, i j}-\frac{q_{b, i j}^{\prime \prime}(t-d)}{k_{S i}} .
$$

The heat flux through the base is calculated from the local net heat transfer rate as

$$
q_{b, i j}^{\prime \prime}=\frac{\dot{q}_{n e t, i j}}{A_{b} / 25} .
$$

The local heat transfer coefficient for each heating element, which represents an average along the channel height at a particular point along the flow length, is calculated considering the microchannel walls as extended fins, according to

$$
h_{i j}=\frac{q_{w, i j}^{\prime \prime}}{\eta_{o}\left(T_{w, i j}-T_{f, i}\right)},
$$

where $q_{w}^{\prime \prime}$ is the wall heat flux calculated using the net heat transfer rate $\dot{q}_{n e t}$ and the total wetted area of the microchannels $A_{w} \cdot \eta_{o}$ is the overall surface efficiency of the microchannel heat sink, defined as

$$
\eta_{o}=1-\frac{N A_{f}}{A_{w}}\left(1-\eta_{f}\right)
$$

where $A_{f}$ represents the wetted area of a microchannel fin and $\eta_{f}$ is the efficiency of a fin with an adiabatic tip. This adiabatic assumption is valid due to the heat transfer to the cover plate being significantly lower than the heat transfer to the liquid in the microchannels. It is calculated as

$$
\eta_{f}=\frac{\tanh m d}{m d}
$$

where

$$
m^{2}=\frac{2 h}{k_{S i} w_{f}} .
$$

The heat transfer coefficient is initially calculated assuming an overall surface efficiency of $100 \%$ and is iterated by calculating new values for efficiency until the value of the heat transfer coefficient converges. The overall efficiencies of the microchannel heat sink were found to be above $95.6 \%$ for all cases. 


\section{Results and Discussion}

The results are split into two heating cases as previously described: (1) hotspots that span the length or width of the heat sink tested with increasing power input against an unpowered background, and (2) non-uniform heating conditions with a peak along the width or length of the heat sink.

In cases 1a through 1c, 5 of the 25 individual heating elements are powered up to simulate a hotspot while the rest are unpowered. The total power supplied to these heating elements is incremented until the maximum allowable wall temperature is reached. In case $1 \mathrm{~d}$, a dual hotspot, 10 of the 25 individual heating elements are powered up. For the second set of non-uniform heating cases ( $2 a$ and $2 b)$, all of the heating elements are initially supplied the same power level, resembling a uniform heating case. The power to 5 of the 25 heating elements is proportionally incremented, while maintaining a constant total power input to the entire test section.

\subsection{Case 1: Hotspot Heating}

The maximum total power input, maximum local heat flux at that power, and maximum local wall temperature are summarized for all cases in Table 1. For Case 1, as the power input increases, the heat flux to the fluid, $q_{w}^{\prime \prime}$, always reaches a maximum above the active heater elements. The individual trends for each single hot spot are described below. Case 1d is discussed in Supplementary Note 1.

Case 1a (Central Transverse Hotspot): The first heating profile tested was with a central transverse hotspot. The five transverse heater elements located along the center of the flow length were supplied with power, while the remaining 20 were turned off. The maximum heat flux recorded is $24.23 \mathrm{~W} / \mathrm{cm}^{2}$. Even though heat is only generated in 5 of the 25 heater elements, significant lateral conduction causes the remaining 20 heater locations to also experience positive heat fluxes ranging from $0.29 \mathrm{~W} / \mathrm{cm}^{2}$ to 2.73 $\mathrm{W} / \mathrm{cm}^{2}$ for a power input of $32.4 \mathrm{~W}$, with the value depending on distance from the heated elements. The heat flux transferred to the fluid along the flow length for increasing input power levels is shown in Figure 4a.

The wall temperature reaches a maximum at the central transverse strip of powered heater elements. The input power is incremented until the maximum temperature reaches $136.9^{\circ} \mathrm{C}$; further increases would damage the test chip and solder joint. The measured wall temperatures along the flow length for increasing input power levels are shown in Figure $4 \mathrm{~b}$. The wall temperatures downstream of the activated heater elements are higher than at the upstream elements; a difference of $7.93{ }^{\circ} \mathrm{C}$ exists between the inlet and outlet at a power input of $32.4 \mathrm{~W}$ due to the temperature rise of the bulk fluid. The maximum bulk fluid temperature is calculated to be $99.1^{\circ} \mathrm{C}$ (the local saturation temperature at the measured pressure); the largest bulk fluid temperature gradient is observed as fluid flows over the hotspot. 
Boiling curves are constructed from the heat flux transferred to the fluid and the wall excess temperature, and are shown in Figure 5 for sensors 3,13, and 23. The wall excess temperature is calculated with respect to the local bulk fluid temperature in the case of single-phase flow, and the saturation temperature in two-phase operation. As the heat flux is increased, the slope of the curve is initially constant, reflecting the relatively constant single-phase heat transfer coefficient. For the upstream and downstream sensors, which are not actively powered, the heat flux is initially negative because the fluid is hotter than the wall and transfers heat to the substrate; this continues until a higher power input is reached and the active strip of heaters spreads heat to these locations. Boiling begins at the heated sensor location at a local heat flux of $16.8 \mathrm{~W} / \mathrm{cm}^{2}$ and a $38.2{ }^{\circ} \mathrm{C}$ excess temperature, and is indicated by the increased slope in the boiling curve. This incipience of boiling is confirmed via in situ visualization (shown in Supplementary Video 1). Lower power input levels produced bubbly flow while an increased power input led to slug flow. At the largest power input, large vapor regions can be seen. All visualizations shown herein have a field of view that captures the boiling behavior over the entire test chip. After boiling incipience occurs at sensor 13, the downstream wall temperature at sensor 23 decreases; the increased (two-phase) heat transfer coefficient at the heated sensor location draws a larger percentage of the heat out of the center and keeps it from spreading by conduction to the outlet.

Case 1b (Central Streamwise Hotspot): The next heating profile tested was with a central streamwise hotspot, with only the five streamwise heater elements located along the center of the heat sink powered. In the streamwise direction, the largest heat flux occurs at the inlet; while the heat flux has a local peak at the location of boiling, the global maximum occurs at the inlet due to entrance effects. As in Case 1a, there is significant lateral conduction through the chip, and the remaining 20 sensors have small positive heat fluxes ranging from $0.80 \mathrm{~W} / \mathrm{cm}^{2}$ to $4.37 \mathrm{~W} / \mathrm{cm}^{2}$ at a total power input of $25.6 \mathrm{~W}$. The heat flux to the fluid is plotted across the central transverse temperature sensors for increasing power input levels in Figure 6a. The trends in the flow direction along the single strip of active heaters closely resemble the uniform heating trends presented later in this work for Case $2 b$; however, significant differences are observed transverse to the flow direction.

As the power input increases, the wall temperature is always highest at the hotspot. Along the hotspot in the streamwise direction, the highest wall temperature occurs at the outlet, as would be observed in a uniform heating case under similar conditions. The wall temperatures measured across the central transverse sensors at increasing input power levels to the hotspot elements are plotted in Figure $6 \mathrm{~b}$. The maximum allowable operating temperature in the chip is reached at a total power input that is lower by $26.6 \%$ for the streamwise hot spot compared to the transverse hot spot, due to the bulk fluid temperature increase along the flow length in the streamwise case. Along the hotspot, the fluid temperature reaches the saturation temperature roughly halfway along the flow length. 
Boiling curves (wall heat flux versus excess temperature at the wall) are shown in Figure 7 for sensors 3, 13, and 23. Up to a total power input of $18.4 \mathrm{~W}$, the streamwise hotspot channels exhibit single-phase operation. The steeper slope for the inlet sensor in the boiling curve is attributed to entrance effects. Boiling only occurs in the hotspot channels, and begins at a heat flux of $8.80 \mathrm{~W} / \mathrm{cm}^{2}$ and a wall excess temperature of $26.9^{\circ} \mathrm{C}$ at the outlet (high-speed visualizations at this condition are shown in Supplementary Video 2). As the power level increases, the location of incipience of boiling advances closer to the inlet. As this occurs, the heat flux transferred to the fluid decreases at the outlet (while the wall temperature upon dryout continues to increase) due to conduction spreading toward the lower temperature upstream area.

Case 1c (Inlet Transverse Hotspot): A transverse hotspot at the inlet, with the first row of elements activated, is considered next. The heat flux to the fluid is plotted across the central streamwise column at increasing power input levels in Figure $8 \mathrm{a}$. It can be seen that $98 \%$ of the input heat is transferred to the fluid over the heated length, which is the first $2.54 \mathrm{~mm}$, or $20 \%$, of the total flow length (compared to $77.6 \%$ for the centrally located heated length in Case 1a). There is less heat spreading in this case compared to Case 1a due to the absence of an upstream flow length to contribute to heat spreading. In addition, the fluid reaches the saturation temperature near the inlet, rendering the downstream portion of the heat sink less effective. This reduces heat spreading to the downstream locations. The flow length downstream of the hotspot is longer than in Case 1a, allowing the outlet wall temperature to decrease below the fluid saturation temperature. The wall temperatures measured along the central streamwise temperature elements with increasing power input levels are shown in Figure 8b. Boiling curves of the wall heat flux versus the excess wall temperature are shown in Figure 9 for sensors 3, 13, and 23. Boiling begins at the inlet hotspot at a heat flux of $23.1 \mathrm{~W} / \mathrm{cm}^{2}$ and a wall excess temperature of $42.5^{\circ} \mathrm{C}$ (highspeed visualizations at this condition are shown in Supplementary Video 3). As in Case 1a, lower power input levels produce bubbly flow while an increased power input leads to slug flow. At higher power levels, long slugs of vapor form at the hotspot and begin to condense at the outlet.

\subsection{Case 2: Non-Uniform Peak-Heating}

The degree of nonuniformity imposed in the distribution of a given total input power to different portions of the chip is quantified by comparing the amount of peak heating to the background heating through the parameter

$$
\Phi=\frac{\frac{Q_{\text {in, high }}}{N_{\text {high }}}-\frac{Q_{\text {in }, \text { low }}}{N_{\text {low }}}}{\frac{Q_{\text {in,total }}}{N_{\text {high }}}}
$$


where $Q_{i n}$ refers to the total power input to the heater elements in a region, and $N$ refers to the number of heater elements in that region. The subscripts high and low refer to the heater element regions at peak and background power inputs, respectively. With this definition, a uniform heating case gives $\Phi=0$ while a hotspot case gives $\Phi=1$.

Case 2a (Non-uniform Transverse Peak): For the central transverse peak heating case, 17 discrete $\Phi$ values were imposed at an average constant total input power level of $33 \mathrm{~W}$. The total power input for each of the peak heating cases studied, along with the maximum local heat fluxes for $\Phi=1$ (hotspot) and $\Phi=0$ (uniform heating), are summarized in Table 2 . The heat flux to the fluid over the flow length for increasing $\Phi$ values is shown in Figure 10a. As the difference between the peak and background heater power levels increases (at a constant total power input), the heat flux to the fluid increases at the central transverse heater elements. The heat flux upstream of the transverse peak-heated strip is greater than that downstream due to the higher heat transfer coefficient at the inlet.

As the degree of nonuniformity $\Phi$ increases, the highest wall temperatures are seen along the transverse central heater elements; however at very low values of $\Phi$, the wall temperature is highest at the outlet as would be expected for a uniform heating case with increasing streamwise temperature in the single-phase fluid. The wall temperatures measured along the flow length for increasing $\Phi$ values are shown in Figure 10b. The maximum wall temperatures range from $128.3^{\circ} \mathrm{C}$ for a uniform case to $136.5^{\circ} \mathrm{C}$ for $\Phi=1$, and occur at different locations. In a uniform case the maximum wall temperature is located at the outlet, while for $\Phi=1$ the maximum wall temperature is located above the peak-heater element.

The heat transfer coefficient was also calculated along the flow length, and is shown in Figure 10c. As the input power nonuniformity $\Phi$ increases, the heat transfer coefficient above the peak-heated region increases. For nonuniformities with $\Phi>0.38$, the highest heat transfer coefficient is observed at the transverse central heater elements, where boiling occurs locally. At the central heater element (sensor 13), the heat transfer coefficient ranges from $1870 \mathrm{~W} / \mathrm{m}^{2} \mathrm{~K}$ for a uniform case to $5970 \mathrm{~W} / \mathrm{m}^{2} \mathrm{~K}$ at $\Phi=1$. Boiling does not occur at the inlet for any of the $\Phi$ values investigated, and therefore the heat transfer coefficient remains unchanged at the upstream locations (sensors 1-10). Once vigorous boiling starts above the heated strip, the heat transfer coefficient at the outlet sees a significant drop. This is similar to the effect seen in the corresponding hotspot case, Case 1a. At large $\Phi$ values, more effective heat transfer at the heated sensor locations reduces the heat available for spreading to the outlet, reducing the local wall temperature and heat flux in the outlet region, but maintaining a high fluid temperature due to upstream boiling.

Figure 11 plots the heat transfer coefficient as a function of temperature difference between the wall and fluid for sensors 3,13 , and 23. Boiling occurs at the peak transverse heat input locations for all $\Phi$ 
values greater than zero. Therefore, as the surface temperature increases with increasing $\Phi$, the heat transfer coefficient at sensor 13 increases significantly, as expected for a boiling regime. The single-phase heat transfer coefficient at the inlet sensor remains relatively constant. The heat transfer coefficient at the outlet sensor increases for the early part of the increase in $\Phi$, and subsequently decreases, even as the wall excess temperature continually decreases. The increase at low $\Phi$ values occurs because of the relatively constant heat flux transferred to the fluid at that location due to heat spreading, coupled with a decrease in the difference between the wall and fluid temperatures. For large $\Phi$ values, the heat transfer coefficient reduction is likely due to a combination of a reduced heat flux (brought about by reduced heat spreading) and a high local vapor quality at the outlet.

High-speed images extracted from videos (Supplementary Video 5) at different degrees of nonuniformity $\Phi$ are shown in Figure 12 for a central transverse peak-heating profile. In the figure, the degrees of nonuniformity of $0.15,0.38,0.66$, and 1.0 are shown; a significant difference in the number of active boiling channels can be seen over this range. For $\Phi=0.15$, boiling does not occur in all of the channels, and some channels display more vigorous boiling than others. As the local heat flux increases, boiling is observed in more of the channels for $\Phi=0.38$, and in all of the channels for $\Phi=0.66$ and for $\Phi=1$. Additionally, the location of boiling incipience moves toward the peak-heated sensors as $\Phi$ increases.

Case 2b (Non-uniform Streamwise Peak): Non-uniform peak heating in the orthogonal direction is tested in Case $2 \mathrm{~b}$ with a central streamwise peak. Fifteen discrete $\Phi$ values were imposed with a constant total input power of $24.4 \mathrm{~W}$. As with the transverse peak, the heat transferred to the fluid peaks at the central streamwise heater elements as the difference between the peak and background heater power $\Phi$ increases. The heat flux to the fluid in the central transverse heater elements for increasing $\Phi$ values is shown in Figure 13.

As $\Phi$ increases, the wall temperature becomes highest at the central heater elements, and increases in the streamwise direction. The maximum wall temperature ranges from $121.2{ }^{\circ} \mathrm{C}$ for a uniform case to $138.7^{\circ} \mathrm{C}$ for $\Phi=1$. The wall temperatures measured along the flow length for increasing $\Phi$ values are shown in Figure 14a. At low values of $\Phi$, the wall temperature continually increases from inlet to outlet, indicating single-phase heat transfer. As $\Phi$ increases to 0.17 , boiling occurs near the outlet and the wall temperatures for the last two sensors become constant while those near the inlet continue to rise. As the location of boiling advances toward the inlet $(\Phi=0.61)$, dryout conditions occur at the outlet and the outlet wall temperature begins to rise again.

As the degree of nonuniformity $\Phi$ is increased, the associated spatial variation of heat transfer coefficient yields insights into the underlying heat transfer mechanisms. The heat transfer coefficients along the flow length are shown for increasing $\Phi$ values in Figure 14b. Initially, for uniform heating 
conditions $(\Phi=0)$, the flow remains entirely in the single-phase regime along the entire channel length. The heat transfer coefficient is greatest at the inlet $\left(3870 \mathrm{~W} / \mathrm{m}^{2} \mathrm{~K}\right)$ due to entrance effects, and asymptotically decreases to a fully developed, constant value $\left(1290 \mathrm{~W} / \mathrm{m}^{2} \mathrm{~K}\right)$. The relative magnitude of this entrance-effect enhancement is similar to that observed in a previous study [24] for uniform heating conditions. With an increase in $\Phi$ to 0.17 , the upstream trend remains similar; however, boiling incipience occurs near the outlet, and the heat transfer coefficient increases at this location. As $\Phi$ increases further, the location of boiling incipience advances upstream, and the associated heat transfer coefficient increase propagates in the same direction. Ultimately, boiling occurs at the inlet, and a maximum heat transfer coefficient of $4440 \mathrm{~W} / \mathrm{m}^{2} \mathrm{~K}$ is observed at this location for $\Phi=1$. At the outlet, while the heat transfer coefficient initially increases as boiling occurs and moves upstream, the heat transfer coefficient decreases as the nonuniformity reaches $\Phi=0.61$. This is indicative of partial dryout in the downstream ends of the central channels.

The heat transfer coefficient is shown as a function of wall excess temperature in Figure 15 for sensors 3, 13, and 23. In this case, boiling begins at the outlet at a low value of $\Phi$ and the location moves upstream at higher $\Phi$ values. As the location of boiling moves upstream, the heat transfer coefficient at the middle sensor increases sharply. The heat transfer coefficient at the outlet sensor peaks and then begins to decrease at higher $\Phi$ values as the more effective boiling incipience regime moves upstream. Boiling only occurs at the central strip of streamwise heater elements shown in the figure.

Images extracted from high-speed videos (Supplementary Video 6) at different degrees of nonuniformity $\Phi$ are shown in Figure 16 for a central streamwise peak-heating profile; degrees of nonuniformity of $0.01,0.23,0.61$, and 1.0 are shown. Boiling does not occur in all of the channels for all values of $\Phi$. At high $\Phi$ values, significant flow reversal can be seen in the central channels above the peak-heated sensors, causing flow maldistribution in the heat sink and partial dryout at the outlet. At these large values the heated channels contain a very large amount of vapor while neighboring channels exhibit bubbly flow. Boiling in the channels associated with the peak-heated elements causes an increase in the local pressure drop, forcing both liquid and vapor bubbles back into the inlet manifold. Vapor in the inlet manifold reroutes to channels with lower flow resistance where little or no boiling occurs. A reduced flow rate in the channels above the peak-heated sensors causes the remaining liquid to vaporize entirely, causing partial dryout. Once a significant amount of vapor leaves the channel through the outlet, the pressure equalizes, liquid flows back into the channels above the peak-heated sensors, and the process repeats.

\section{Conclusions}


The effects of non-uniform hot spots and heating profiles in a microchannel heat sink on heat transfer coefficients, wall temperatures, and the location of boiling incipience were investigated. To properly assess the local heat dissipation under non-uniform heating conditions, lateral conduction through the microchannel heat sink base was taken into account. Experimental results show that even with a very thin substrate, significant lateral conduction occurs in the base of the heat sink.

Single hotspots that span the width or length of a silicon microchannel heat sink were investigated as a function of increasing local heat flux. In the case of a transverse hotspot in the center of the heat sink, once boiling begins in the heated sensor location, the wall temperature at the outlet decreases and conduction away from the center is mitigated due to reduced convection thermal resistance. In the case of a streamwise hotspot along the central column of the heat sink, conduction causes some lateral heating, but boiling only occurs in the channels located above the hotspot. In this configuration, the maximum sustainable total power input achieved is reduced by $26.6 \%$ compared to the transverse hotspot case. In the case of a transverse hotspot located at the inlet, although the maximum sustainable total power input is similar to the central transverse hotspot, the local maximum heat flux is increased by $35.7 \%$ as a result of significantly reduced upstream heat spreading. These test cases show that the same total power input distributed in different locations and configurations across the heat sink can cause significantly different limits on the maximum heat fluxes and wall temperatures that can be supported.

A second non-uniform heating condition was investigated to understand the effect of the degree of nonuniformity imposed in the distribution of a given total input power to different portions of the chip, by incrementing the nonuniformity between the peak and background heat flux values. For non-uniform transverse peak-heating profiles, an increase in the heating nonuniformity results in significant boiling at the location of the peak heat input, whereas no boiling occurs under uniform heating conditions. For nonuniform streamwise peak-heating profiles, an increase in the heating nonuniformity for a constant total power input results in boiling at the location of the peak heat input location; the location of boiling incipience moves upstream as the nonuniformity increases. For both hotspot and peak heating in the streamwise direction, significant flow reversal is observed leading to dryout in the channels above the peak heated region. In both cases, the local heat transfer coefficients and wall temperatures deviate significantly from a uniformly heated case. Local heat flux concentrations result in high local two-phase flow heat transfer coefficients, but at the expense of increased wall temperatures.

\section{Acknowledgements}

Financial support for this work was provided by the Cooling Technologies Research Center, a National Science Foundation Industry/University Cooperative Research Center at Purdue University. The 
authors thank Bruce Myers and Darrel Peugh of Delphi Electronics and Safety, Kokomo, Indiana, for providing the silicon microchannel heat sink test chip.

\section{Nomenclature}

$$
\begin{aligned}
& A_{b} \quad \text { heat sink base area }\left(\mathrm{m}^{2}\right) \\
& A_{f} \quad \text { wetted area of a fin }\left(\mathrm{m}^{2}\right) \\
& A_{w} \quad \text { total wetted area of the microchannels }\left(\mathrm{m}^{2}\right) \\
& c_{p} \quad \text { specific heat }\left(\mathrm{J} \mathrm{m}^{-2} \mathrm{~K}^{-1}\right) \\
& \text { d microchannel depth (m) } \\
& \text { G mass flux }\left(\mathrm{kg} \mathrm{m}^{-2} \mathrm{~s}^{-1}\right) \\
& h \quad \text { heat transfer coefficient }\left(\mathrm{W} \mathrm{m}^{-2} \mathrm{~K}^{-1}\right) \\
& k_{S i} \quad \text { thermal conductivity of silicon }\left(\mathrm{W} \mathrm{m}^{-1} \mathrm{~K}^{-1}\right) \\
& L \quad \text { heat sink width (m) } \\
& m \quad \text { variable in fin efficiency calculation }\left(\mathrm{m}^{-1}\right) \\
& N \quad \text { number of microchannels, heaters } \\
& \text { Q power input (W) } \\
& q_{b}^{\prime \prime} \quad \text { base heat flux }\left(\mathrm{W} \mathrm{m}^{-2}\right) \\
& \dot{q}_{\text {cond }} \text { heat conduction (W) } \\
& \dot{q}_{\text {gen }} \text { heat generation (W) } \\
& \dot{q}_{\text {loss }} \text { heat loss (W) } \\
& \dot{q}_{\text {net }} \quad \text { total heat transferred to the fluid (W) } \\
& q_{w}^{\prime \prime} \quad \text { wall heat flux }\left(\mathrm{W} \mathrm{m}^{-2}\right) \\
& T_{d} \quad \text { diode temperature (C) } \\
& T_{f} \quad \text { fluid temperature (C) } \\
& T_{\text {in }} \quad \text { inlet fluid temperature (C) } \\
& T_{w} \quad \text { wall temperature (C) } \\
& t \quad \text { heat sink thickness (m) } \\
& \text { w microchannel width (m) } \\
& w_{f} \quad \text { fin width (m) }
\end{aligned}
$$

Greek Symbols

$$
\begin{array}{ll}
\eta_{f} & \text { fin efficiency } \\
\eta_{o} & \text { overall heat sink efficiency } \\
\Phi & \text { degree of nonuniformity }
\end{array}
$$


Subscripts

$\begin{array}{ll}\text { high } & \text { peak-heater element region } \\ i & \text { heater element in the flow direction } \\ j & \text { heater element in the transverse direction } \\ \text { low } & \text { background heater element region }\end{array}$

\section{References}

[1] J.F. Tullius, R. Vajtai, Y. Bayazitoglu, A review of cooling in microchannels, Heat Transfer Engineering 32 (2011) 527-541.

[2] S.V. Garimella, T. Harirchian, Encyclopedia of Thermal Packaging, Volume 1: Microchannel Heat Sinks for Electronics Cooling, World Scientific, Singapore, 2013.

[3] C.B. Tibirica, G. Ribatski, Flow boiling in micro-scale channels - synthesized literature review, International Journal of Refrigeration 36 (2013) 301-324.

[4] D. Liu, P.S. Lee, S.V. Garimella, Prediction of the onset of nucleate boiling in microchannel flow, International Journal of Heat and Mass Transfer 48 (2005) 5134-5149.

[5] P.S. Lee, S.V. Garimella, Saturated flow boiling heat transfer and pressure drop in silicon microchannel arrays, International Journal of Heat and Mass Transfer 51 (2008) 789-806.

[6] T. Harirchian, S.V. Garimella, Microchannel size effects on local flow boiling heat transfer to a dielectric fluid, International Journal of Heat and Mass Transfer 51 (2008) 3724-3735.

[7] S.S. Bertsch, E.A. Groll, S.V. Garimella, Effects of heat flux, mass flux, vapor quality, and saturation temperature on flow boiling heat transfer in microchannels, International Journal of Multiphase Flow 35 (2009) 142-154.

[8] E. Costa-Patry, J. Olivier, B. Michel, J.R. Thome, Two-phase flow of refrigerants in 85 um-wide multi-microchannels: part II - heat transfer with 35 local heaters, International Journal of Heat and Fluid Flow 32 (2011) 464-476.

[9] R. Revellin, J.R. Thome, A theoretical model for the prediction of the critical heat flux in heated microchannels, International Journal of Heat and Mass Transfer (2008) 1216-1225.

[10] A. Kosar, A model to predict saturated critical heat flux in minichannels and microchannels, International Journal of Thermal Sciences 48 (2009) 261-270.

[11] T.Y. Liu, P.L. Li, C.W. Liu, C. Gau, Boiling flow characteristics in microchannels with very hydrophobic surface to super-hydrophilic surface, International Journal of Heat and Mass Transfer 54 (2011) 126-134. 
[12] T. Harirchian, S.V. Garimella, A comprehensive flow regime map for microchannel flow boiling with quantitative transition criteria, International Journal of Heat and Mass Transfer 53 (2010) 2694-2702.

[13] H.F. Hamann, A. Weger, J.A. Lacey, Z. Hu, P. Bose, E. Cohen, J. Wakil, Hotspot-limited microprocessors: direct temperature and power distribution measurements, IEEE Journal of Solid State Circuits 42 (2007) 56-65.

[14] J.M. Koo, L. Jiang, A. Bari, L. Zhang, E. Wang, T.W. Kenny, J.G. Santiago, K.E. Goodson, Convective boiling in microchannel heat sinks with spatially-varying heat generation, in: Proceedings of the ASME $8^{\text {th }}$ Intersociety Conference on Thermal and Thermomechanical Phenomena in Electronic Systems (ITHERM), San Diego, CA, 2002, pp. 341-346.

[15] R.K. Sarangi, A. Bhattacharya, R.S. Prasher, Numerical modeling of boiling heat transfer in microchannels, Applied Thermal Engineering 29 (2009) 300-309.

[16] R. Revellin, J.M. Quiben, J. Bonjour, J.R. Thome, Effect of local hot spots on the maximum dissipation rates during flow boiling in a microchannel, IEEE Transactions on Components and Packaging Technologies 31 (2008) 407-416.

[17] D. Bogojevic, K. Sefiane, A.J. Walton, H. Lin, G. Cummins, D.B.R. Kenning, T.G. Karayiannis, Experimental investigation of non-uniform heating on flow boiling instabilities in a microchannels based heat sink, in: Proceedings of the ASME $7^{\text {th }}$ International Conference on Nanochannels, Microchannels and Minichannels (ICNMM), Pohang, South Korea, 2009.

[18] E.S. Cho, J.W. Choi, J.S. Yoon, M.S. Kim, Experimental study on microchannel heat sinks considering mass flow distribution with non-uniform heat flux conditions, International Journal of Heat and Mass Transfer 53 (2010) 2159-2168.

[19] E. Costa-Patry, Cooling high heat flux micro-electronic systems using refrigerants in high aspect ratio multi-microchannel evaporators, $\mathrm{PhD}$ thesis, Ecole Polytechnique Federale De Lausanne, Lausanne, Switzerland, 2011.

[20] T. Alam, P.S. Lee, C.R. Yap, L. Jin, A comparative study of flow boiling heat transfer and pressure drop characteristics in microgap and microchannel heat sink and an evaluation of microgap heat sink for hotspot mitigation, International Journal of Heat and Mass Transfer 58 (2013) 335-347.

[21] J.L. Miler, R. Flynn, G. Refai-Ahmed, M. Touzelbaev, M. David, J. Steinbrenner, K.E. Goodson, Effects of transient heating on two-phase flow response in microchannel heat exchangers, in: Proceedings of the ASME 2009 InterPACK Conference, San Francisco, CA, 2009.

[22] T. Chen, S.V. Garimella, Effect of dissolved air on subcooled flow boiling of a dielectric coolant in a microchannel heat sink, Journal of Electronic Packaging 128 (2006) 398-404. 
[23] T. Chen, S.V. Garimella, Measurements and high-speed visualization of flow boiling of a dielectric fluid in a silicon microchannel heat sink, International Journal of Multiphase Flow 32 (2006) 957971.

[24] R.S. Patel, T. Harirchian, S.V. Garimella, Dependence of flow boiling heat transfer coefficient on location and vapor quality in a microchannel heat sink, in: Proceedings of the Pacific Rim Technical Conference \& Exposition on Packaging and Integration of Electronic and Photonic Systems (InterPACK), Portland, OR, 2011. 


\section{List of Tables}

Table 1. Summary of results for the hotspot heating cases.

Table 2. Summary of results for the peak heating cases. 
Table 1. Summary of results for the hotspot heating cases.

\begin{tabular}{cccc}
\hline & $\begin{array}{c}\text { Maximum Total } \\
\text { Power Input }(\mathrm{W})\end{array}$ & $\begin{array}{c}\text { Maximum Local } \\
\text { Heat Flux }\left(\mathrm{W} / \mathrm{cm}^{2}\right)\end{array}$ & $\begin{array}{c}\text { Maximum Local Wall } \\
\text { Temperature }\left({ }^{\circ} \mathrm{C}\right)\end{array}$ \\
\hline $\begin{array}{c}\text { Case 1a: Central } \\
\text { transverse hotspot }\end{array}$ & 32.4 & 24.23 & 136.9 \\
\hline $\begin{array}{c}\text { Case 1b: Central } \\
\text { streamwise hotspot }\end{array}$ & 25.6 & 16.14 & 146.3 \\
\hline $\begin{array}{c}\text { Case 1c: Inlet } \\
\text { transverse hotspot }\end{array}$ & 35.8 & 32.89 & 138.8 \\
\hline $\begin{array}{c}\text { Case 1d: Dual } \\
\text { transverse hotspots }\end{array}$ & 65.0 & 32.21 & 133.7 \\
\hline
\end{tabular}

Table 2. Summary of results for the peak heating cases.

\begin{tabular}{cccc}
\hline & $\begin{array}{c}\text { Total Power } \\
\text { Input }(\mathrm{W})\end{array}$ & $\begin{array}{c}\text { Maximum Local Heat } \\
\text { Flux, } \Phi=1\left(\mathrm{~W} / \mathrm{cm}^{2}\right)\end{array}$ & $\begin{array}{c}\text { Maximum Local Heat } \\
\text { Flux, } \Phi=0\left(\mathrm{~W} / \mathrm{cm}^{2}\right)\end{array}$ \\
\hline $\begin{array}{c}\text { Case 2a: Non-uniform } \\
\text { transverse peak }\end{array}$ & 33.0 & 23.70 & 8.17 \\
\hline $\begin{array}{c}\text { Case 2b: Non-uniform } \\
\text { streamwise peak }\end{array}$ & 24.4 & 15.29 & 6.23 \\
\hline
\end{tabular}




\section{List of Figures}

Figure 1. (a) Image of the microchannel test section and (b) images of the $5 \times 5$ array of heater elements and a schematic diagram of the microchannel heat sink.

Figure 2. Schematic diagram of the experimental setup showing the flow loop components and highspeed visualization optics.

Figure 3. (a) Hotspot, and (b) non-uniform peak-heating profile configurations investigated in the current study.

Figure 4. (a) Local heat flux transferred to the fluid, and (b) wall temperature along the flow length at increasing power input levels for a central transverse hotspot. The local quantities are presented for the central streamwise elements, as indicated by the dark black rectangle in the heater power diagram.

Figure 5. Heat flux transferred to the fluid plotted against the wall excess temperature for sensors 3, 13, and 23 for a central transverse hotspot.

Figure 6. (a) Local heat flux transferred to the fluid, and (b) wall temperature over the width of the chip for increasing power input levels for a central streamwise hotspot. The local quantities are presented for the transverse elements, as indicated by the black line on the heater power diagram.

Figure 7. Heat flux transferred to the fluid plotted against the wall excess temperature for sensors 3,13 , and 23 for a central streamwise hotspot.

Figure 8. (a) Local heat flux transferred to the fluid, and (b) wall temperature over the length of the chip for increasing power input levels for an inlet transverse hotspot. The local quantities are presented for the streamwise elements, as indicated by the black line on the heater power diagram.

Figure 9. Heat flux transferred to the fluid plotted against the wall excess temperature for sensors 3, 13, and 23 for an inlet transverse hotspot.

Figure 10. (a) Local heat flux transferred to the fluid, (b) wall temperature, and (c) heat transfer coefficient over the flow length at increasing degrees of nonuniformity between the heat flux at the peak and the background heater locations for Case 2a.

Figure 11. The heat transfer coefficient as a function of excess wall temperature for sensors 3, 13, and 23 for Case 2a.

Figure 12. Images at increasing $\boldsymbol{\Phi}$ values for a central transverse peak extracted from high-speed video (Supplementary Video 5). Red lines indicate the locations of the peak-heated sensors.

Figure 13. The local heat flux transferred to the fluid over the width of the chip at increasing degrees of nonuniformity between the heat flux at the peak and background heater location for Case $2 \mathrm{~b}$. 
Figure 14. (a) Local wall temperature, and (b) heat transfer coefficient over the flow length at increasing degrees of nonuniformity between the heat flux at the peak and background heater locations for Case 2b.

Figure 15. The heat transfer coefficient plotted against the wall excess temperature for sensors 3 , 13, and 23 for Case $2 b$.

Figure 16. Images at increasing $\boldsymbol{\Phi}$ values for a central streamwise peak extracted from high-speed video (Supplementary Video 6). Red lines indicate the locations of the peak-heated sensors. 


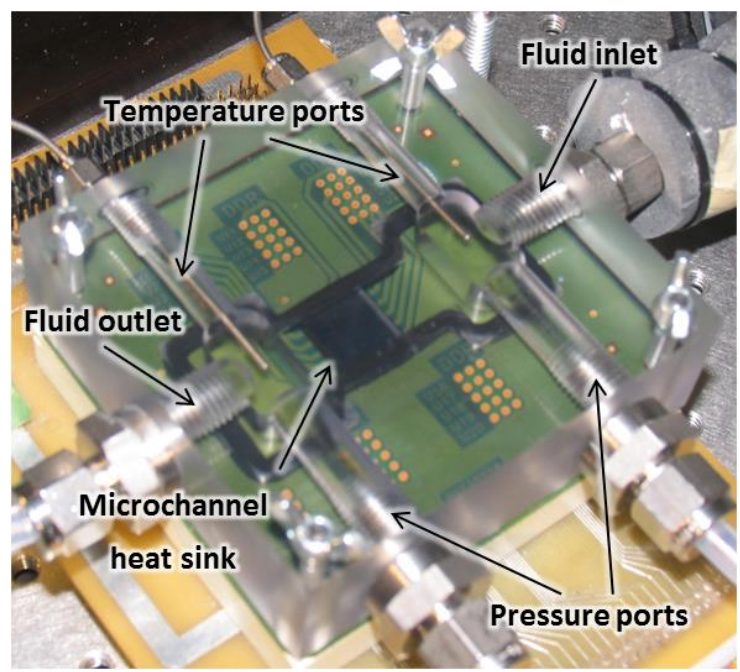

(a)

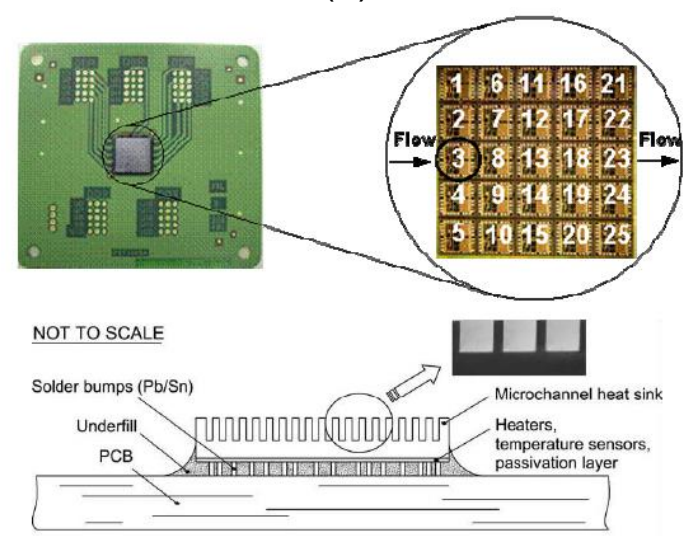

(b)

Figure 1. (a) Image of the microchannel test section and (b) images of the $5 \times 5$ array of heater elements and a schematic diagram of the microchannel heat sink. 


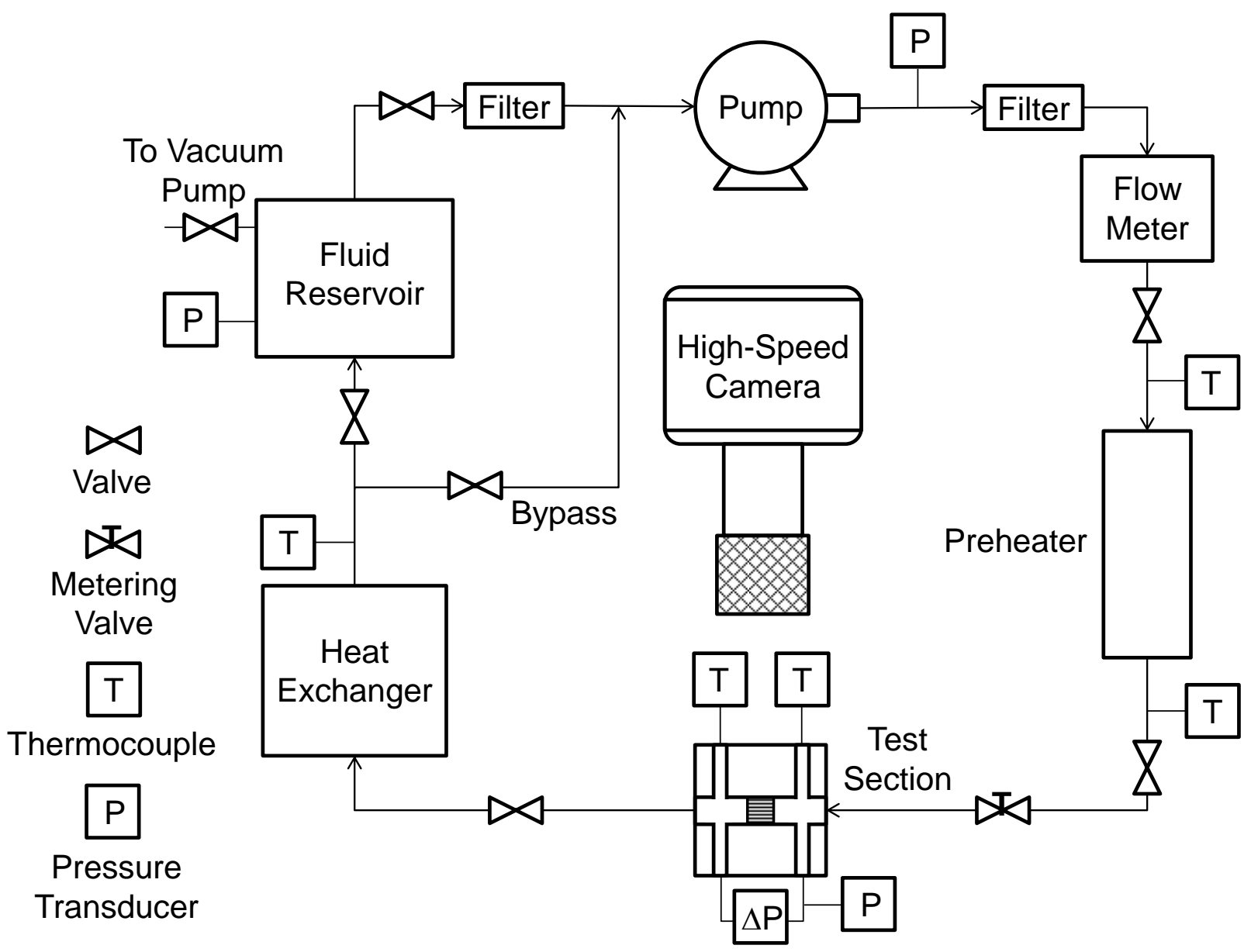

Figure 2. Schematic diagram of the experimental setup showing the flow loop components and highspeed visualization optics. 


\section{Flow direction}

\begin{tabular}{|l|l|l|l|l|}
\hline 1 & 6 & 11 & 16 & 21 \\
\hline 2 & 7 & 12 & 17 & 22 \\
\hline 3 & 8 & 13 & 18 & 23 \\
\hline 4 & 9 & 14 & 19 & 24 \\
\hline 5 & 10 & 15 & 20 & 25 \\
\hline
\end{tabular}

1a: Central transverse hotspot

\begin{tabular}{|l|l|l|l|l|}
\hline 1 & 6 & 11 & 16 & 21 \\
\hline 2 & 7 & 12 & 17 & 22 \\
\hline 3 & 8 & 13 & 18 & 23 \\
\hline 4 & 9 & 14 & 19 & 24 \\
\hline 5 & 10 & 15 & 20 & 25 \\
\hline
\end{tabular}

1c: Inlet transverse hotspot

\begin{tabular}{|c|c|c|c|c|}
\hline 1 & 6 & 11 & 16 & 21 \\
\hline 2 & 7 & 12 & 17 & 22 \\
\hline 3 & 8 & 13 & 18 & 23 \\
\hline 4 & 9 & 14 & 19 & 24 \\
\hline 5 & 10 & 15 & 20 & 25 \\
\hline
\end{tabular}

1b: Central streamwise hotspot

\begin{tabular}{|l|l|l|l|l|}
\hline 1 & 6 & 11 & 16 & 21 \\
\hline 2 & 7 & 12 & 17 & 22 \\
\hline 3 & 8 & 13 & 18 & 23 \\
\hline 4 & 9 & 14 & 19 & 24 \\
\hline 5 & 10 & 15 & 20 & 25 \\
\hline
\end{tabular}

1d: Dual transverse

(a) hotspots

\begin{tabular}{|l|l|l|l|l|}
\hline 1 & 6 & 11 & 16 & 21 \\
\hline 2 & 7 & 12 & 17 & 22 \\
\hline 3 & 8 & 13 & 18 & 23 \\
\hline 4 & 9 & 14 & 19 & 24 \\
\hline 5 & 10 & 15 & 20 & 25 \\
\hline
\end{tabular}

2a: Non-uniform transverse peak

\begin{tabular}{|l|l|l|l|l|}
\hline 1 & 6 & 11 & 16 & 21 \\
\hline 2 & 7 & 12 & 17 & 22 \\
\hline 3 & 8 & 13 & 18 & 23 \\
\hline 4 & 9 & 14 & 19 & 24 \\
\hline 5 & 10 & 15 & 20 & 25 \\
\hline
\end{tabular}

2b: Non-uniform streamwise peak (b)

Figure 3. (a) Hotspot, and (b) non-uniform peak-heating profile configurations investigated in the current study. 

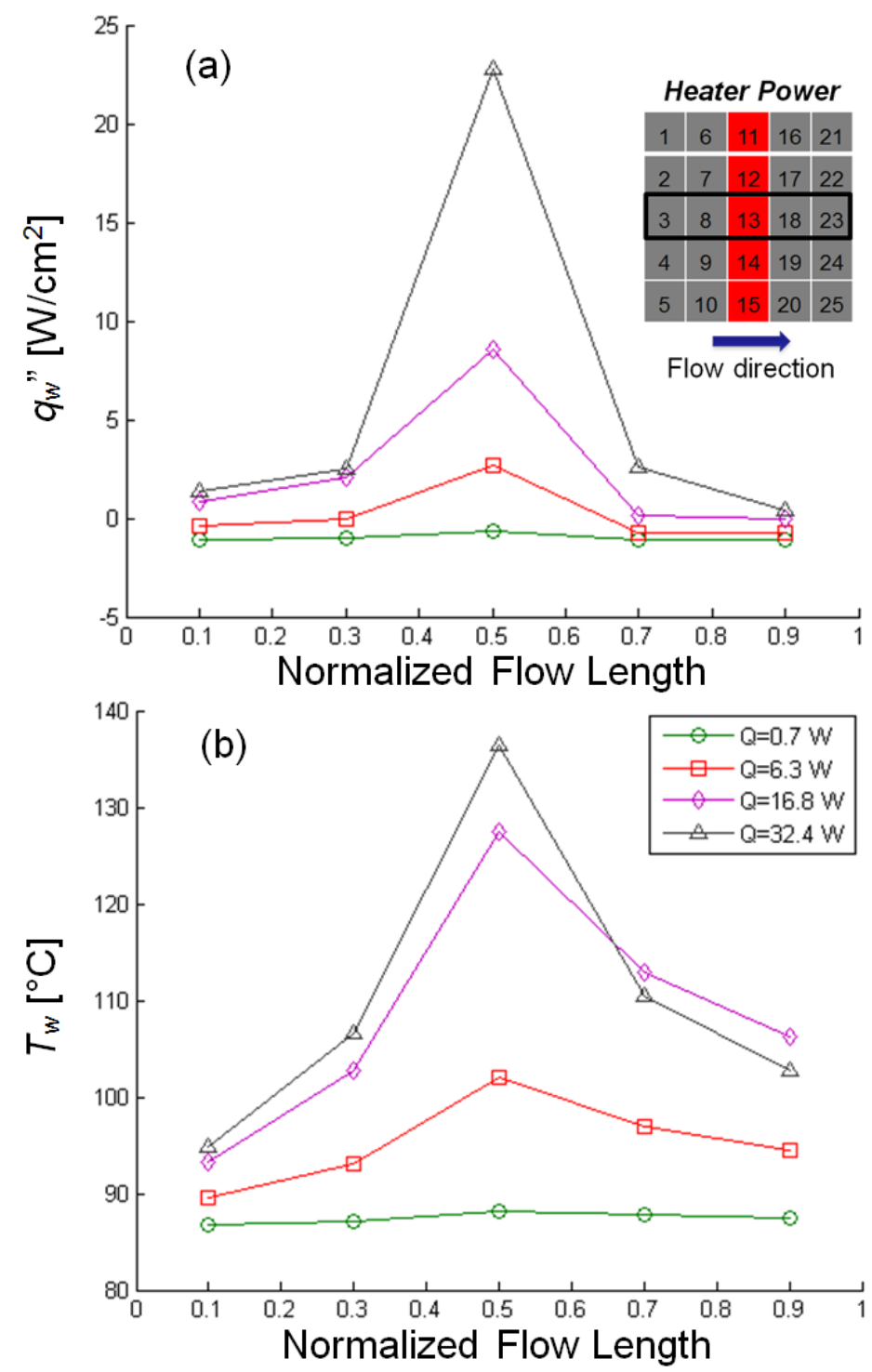

Figure 4. (a) Local heat flux transferred to the fluid, and (b) wall temperature along the flow length at increasing power input levels for a central transverse hotspot. The local quantities are presented for the central streamwise elements, as indicated by the dark black rectangle in the heater power diagram. 


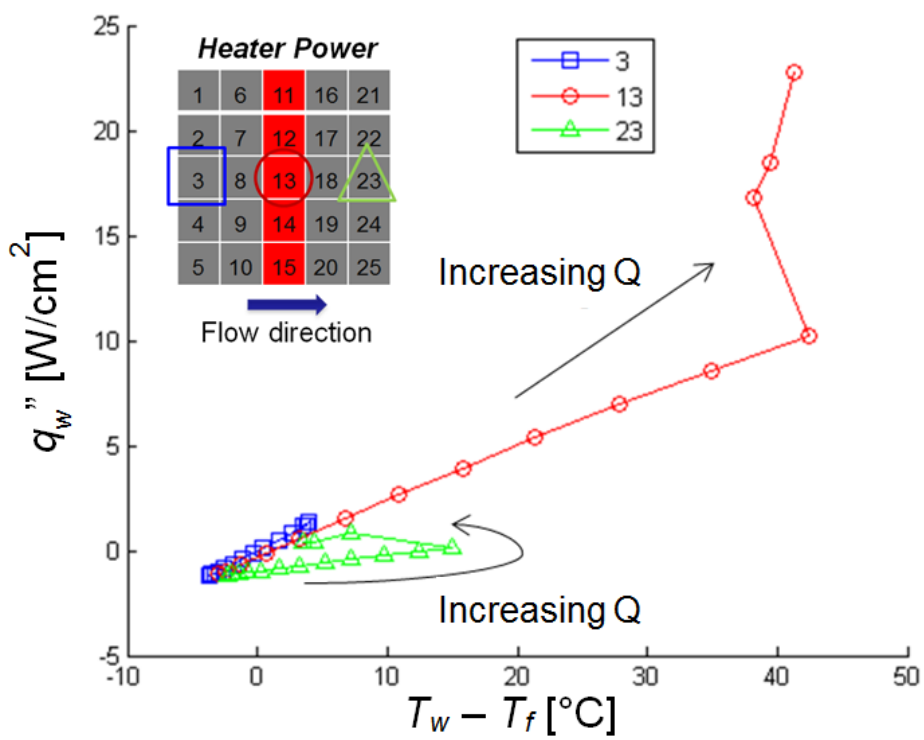

Figure 5. Heat flux transferred to the fluid plotted against the wall excess temperature for sensors 3, 13, and 23 for a central transverse hotspot. 

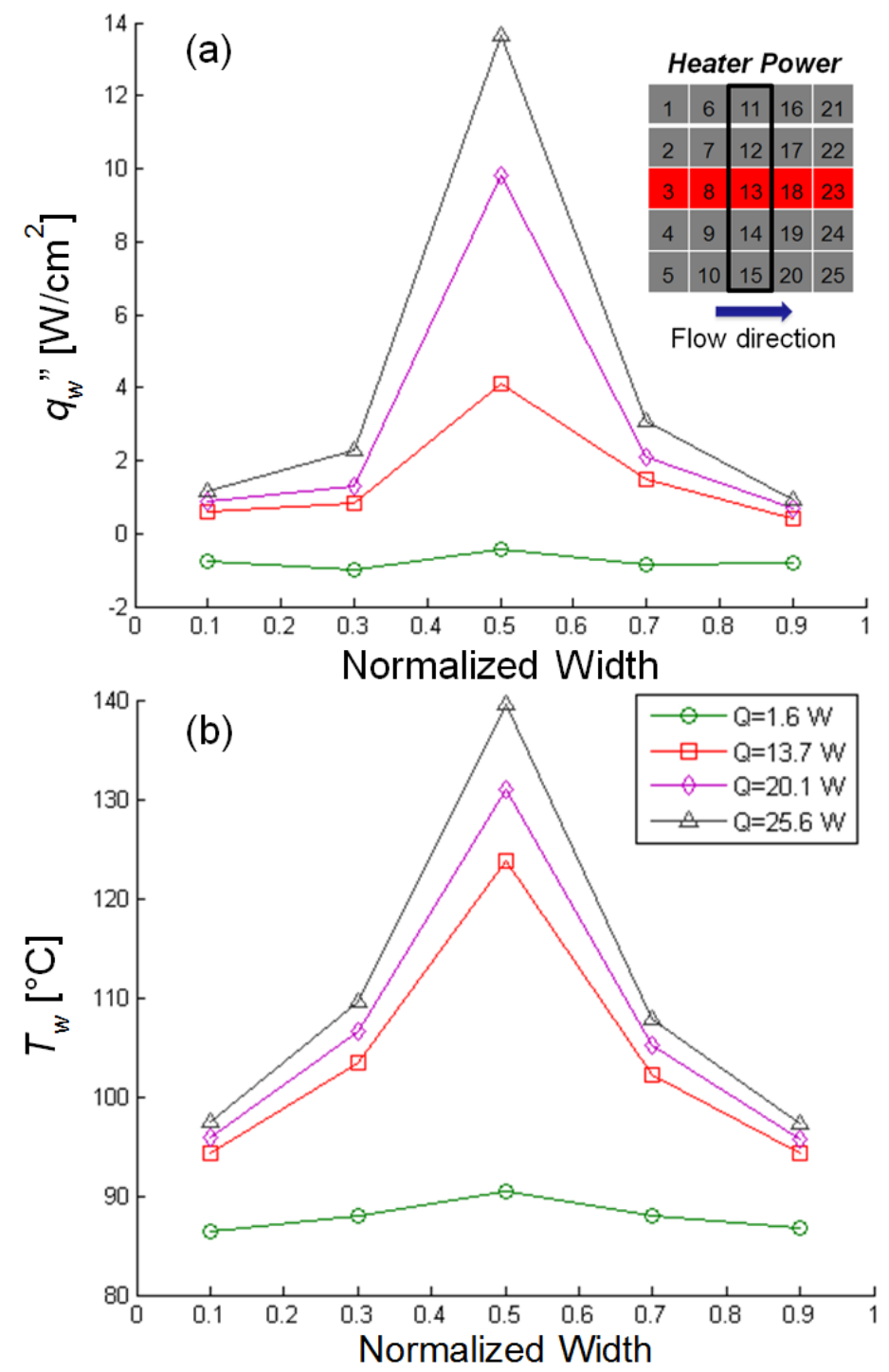

Figure 6. (a) Local heat flux transferred to the fluid, and (b) wall temperature over the width of the chip for increasing power input levels for a central streamwise hotspot. The local quantities are presented for the transverse elements, as indicated by the black line on the heater power diagram. 


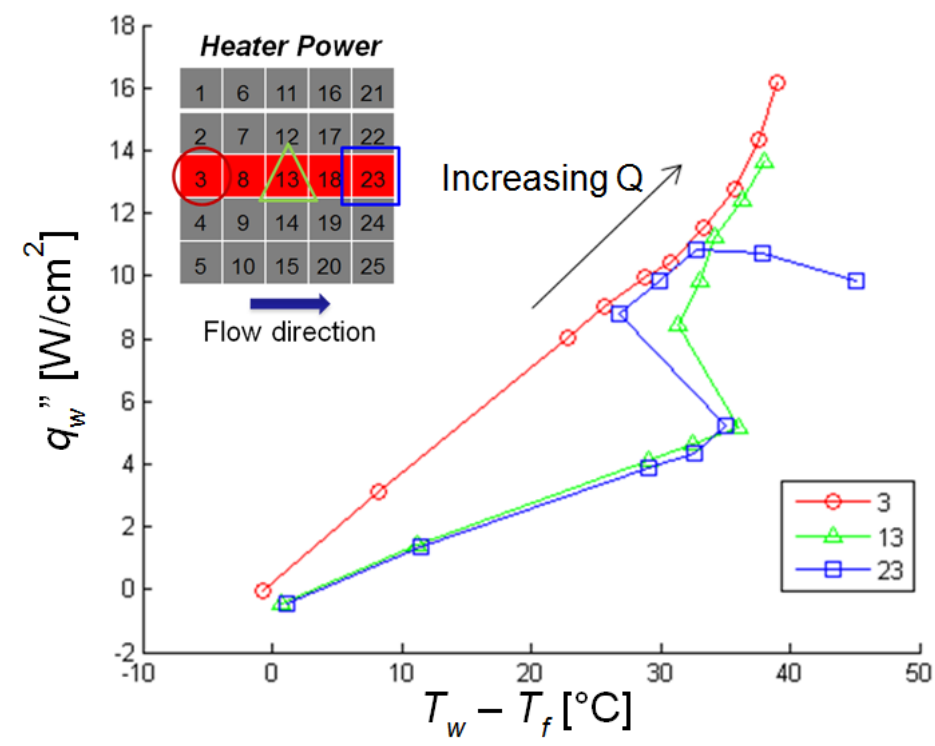

Figure 7. Heat flux transferred to the fluid plotted against the wall excess temperature for sensors 3,13 , and 23 for a central streamwise hotspot. 

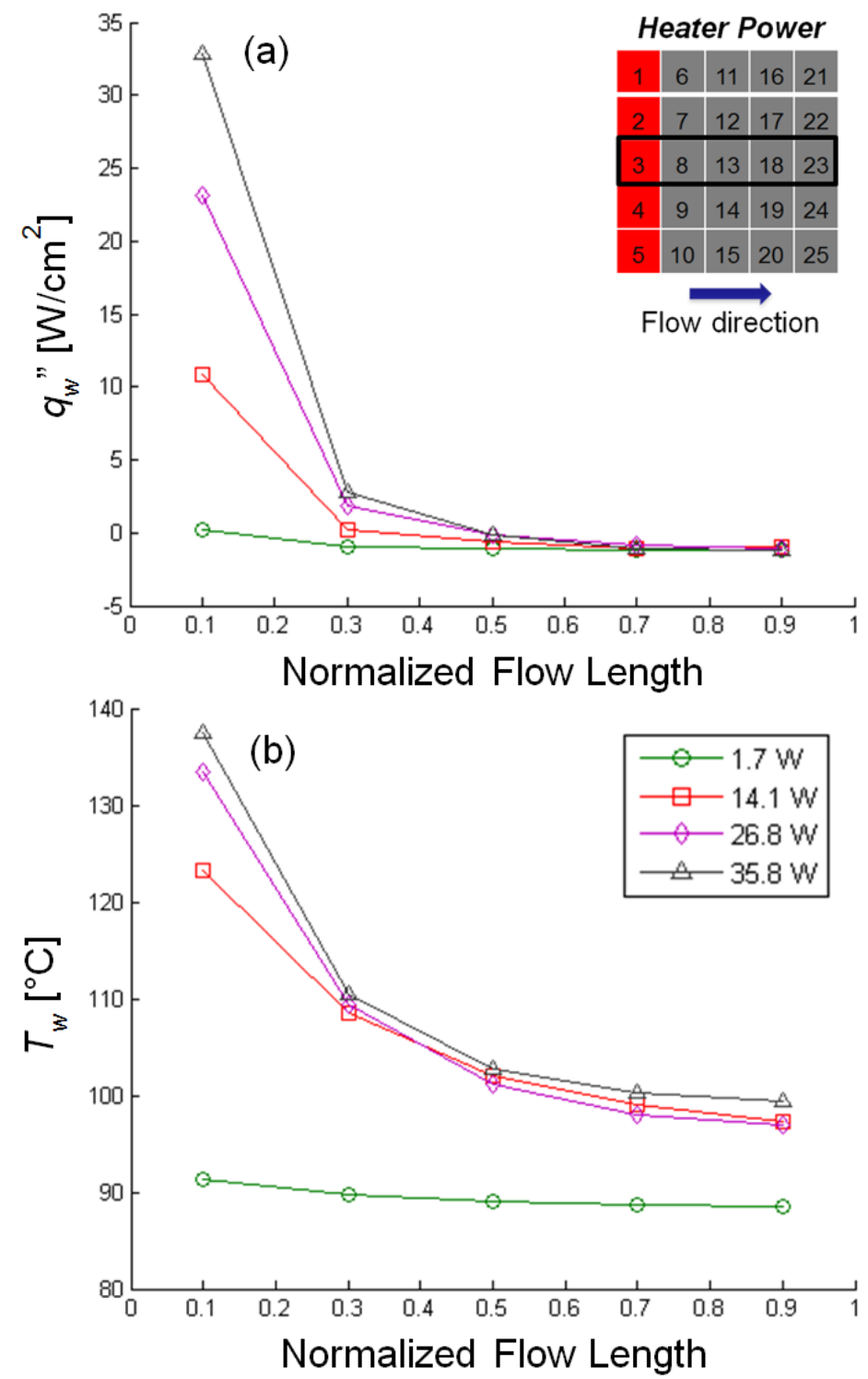

Figure 8. (a) Local heat flux transferred to the fluid, and (b) wall temperature over the length of the chip for increasing power input levels for an inlet transverse hotspot. The local quantities are presented for the streamwise elements, as indicated by the black line on the heater power diagram. 


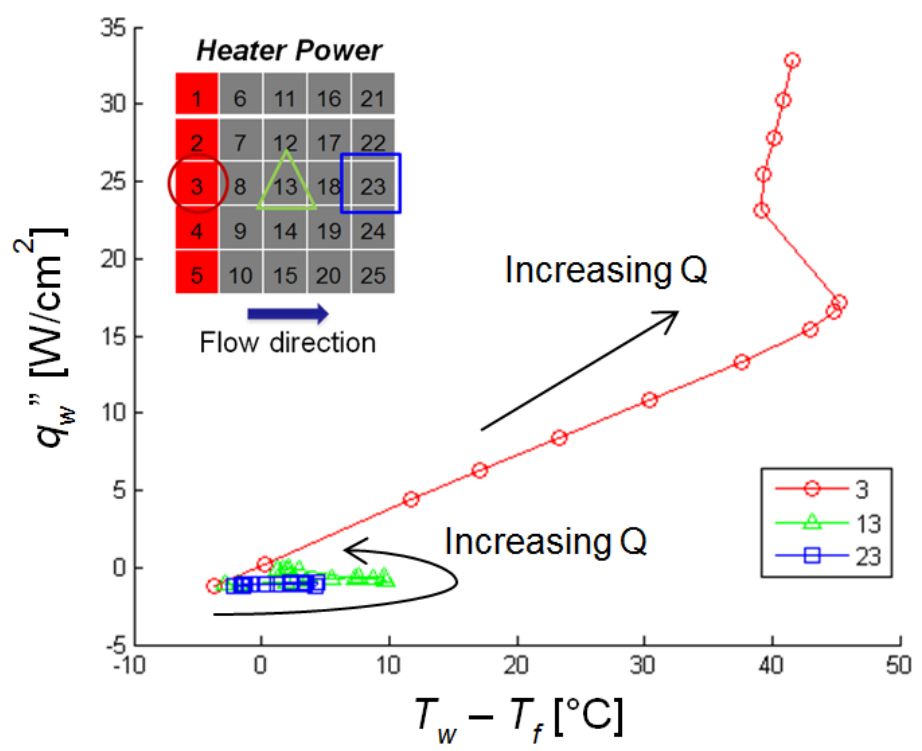

Figure 9. Heat flux transferred to the fluid plotted against the wall excess temperature for sensors 3,13 , and 23 for an inlet transverse hotspot. 

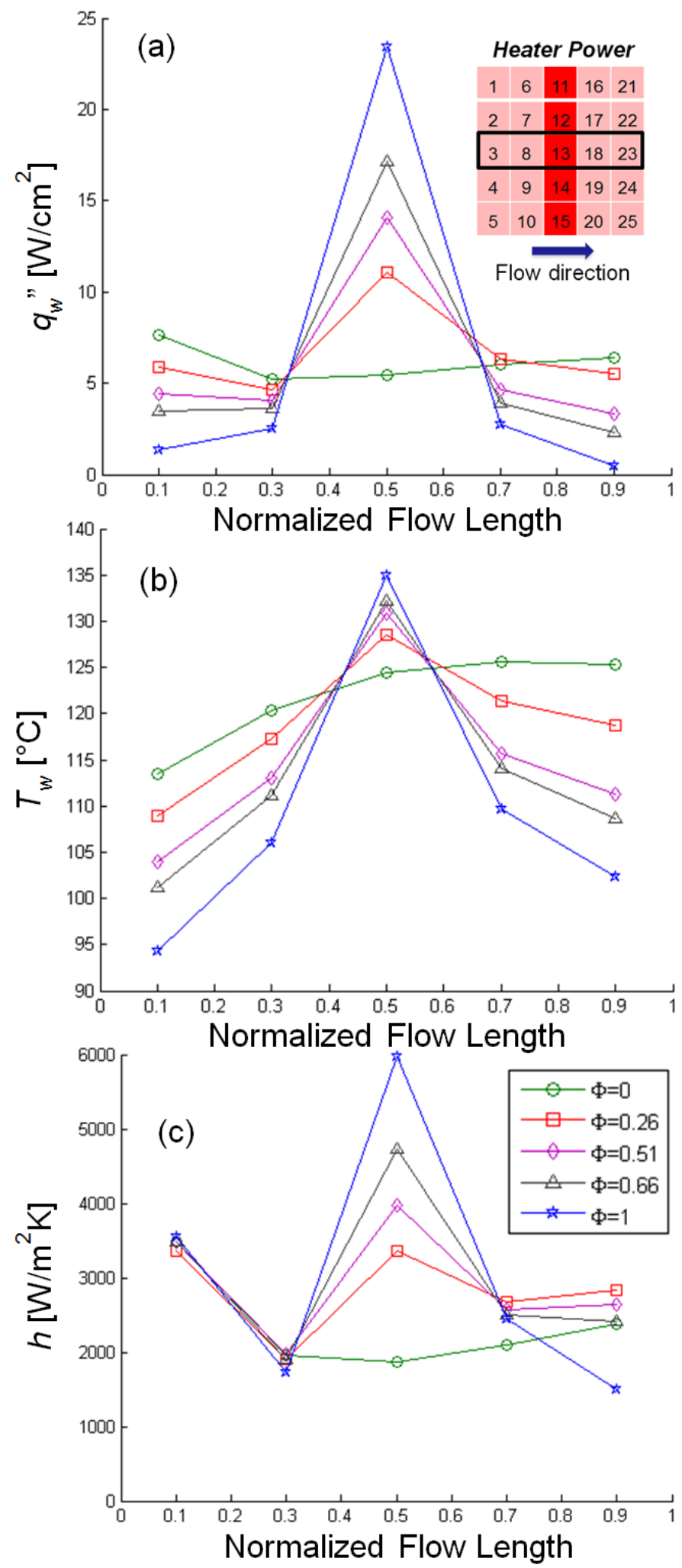

Figure 10. (a) Local heat flux transferred to the fluid, (b) wall temperature, and (c) heat transfer coefficient over the flow length at increasing degrees of nonuniformity between the heat flux at the peak and the background heater locations for Case $2 \mathrm{a}$. 


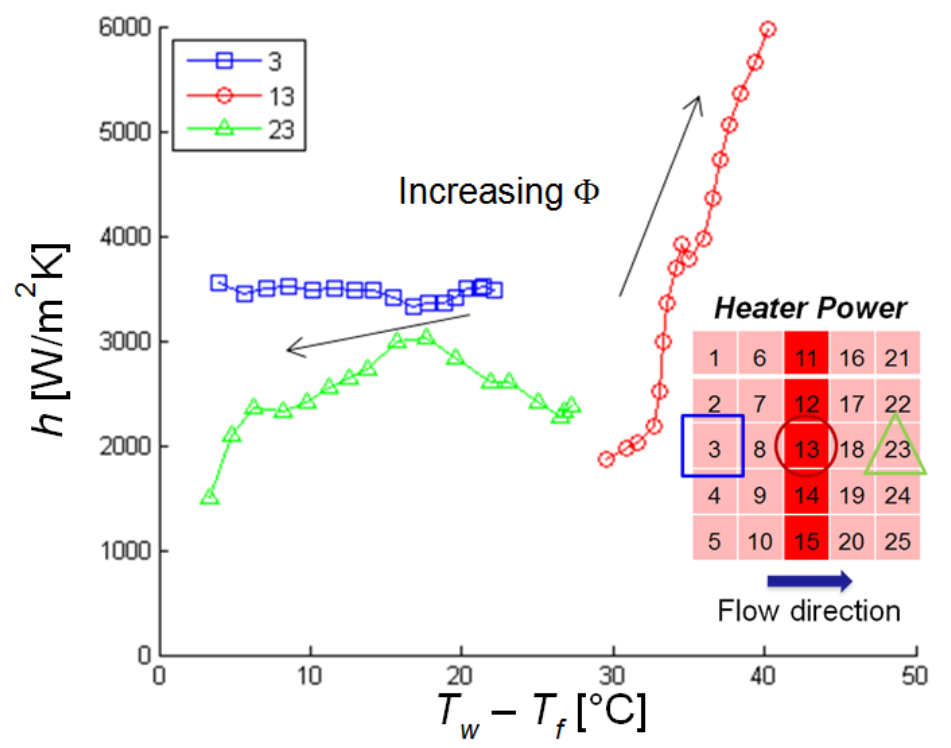

Figure 11. The heat transfer coefficient as a function of excess wall temperature for sensors 3 , 13, and 23 for Case 2a. 

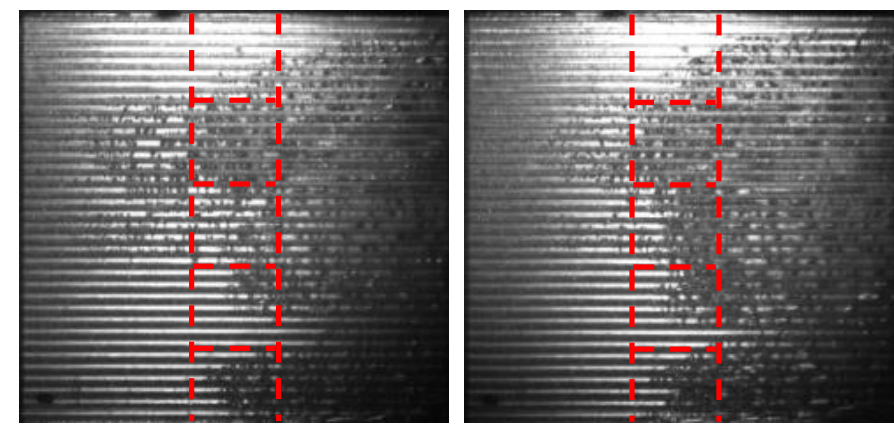

$\Phi=0.15$

$\Phi=0.38$
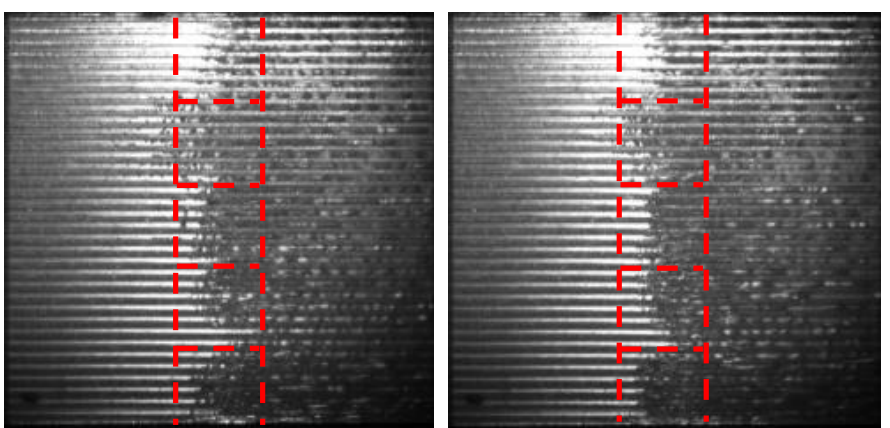

$\Phi=0.66$

$\Phi=1.0$

Figure 12. Images at increasing $\boldsymbol{\Phi}$ values for a central transverse peak extracted from high-speed video (Supplementary Video 5). Red lines indicate the locations of the peak-heated sensors. 


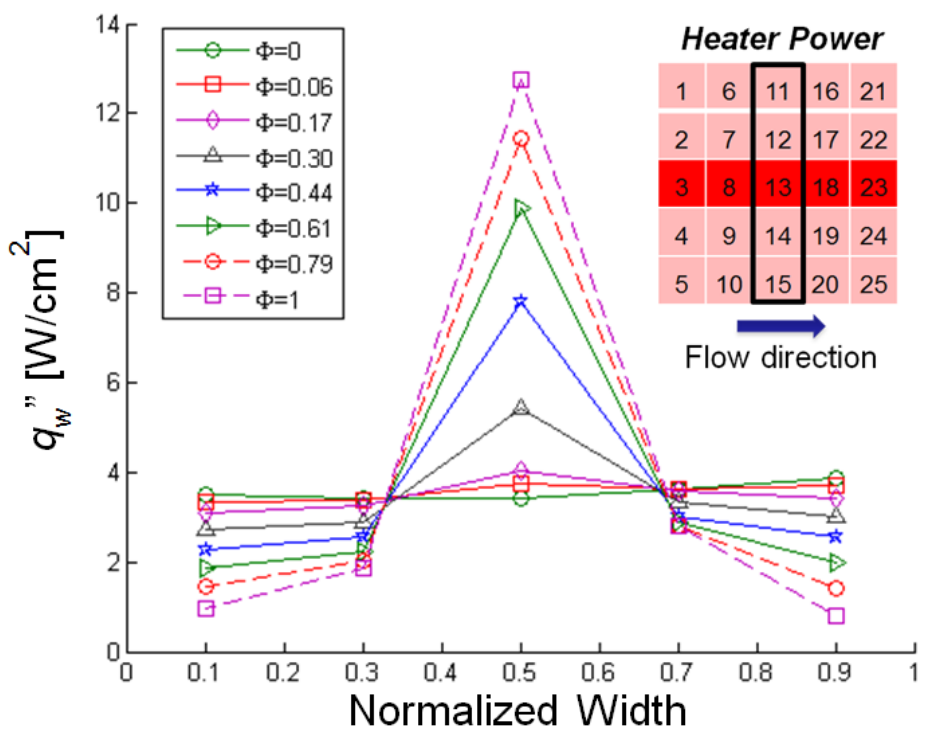

Figure 13. The local heat flux transferred to the fluid over the width of the chip at increasing degrees of nonuniformity between the heat flux at the peak and background heater location for Case $2 \mathrm{~b}$. 

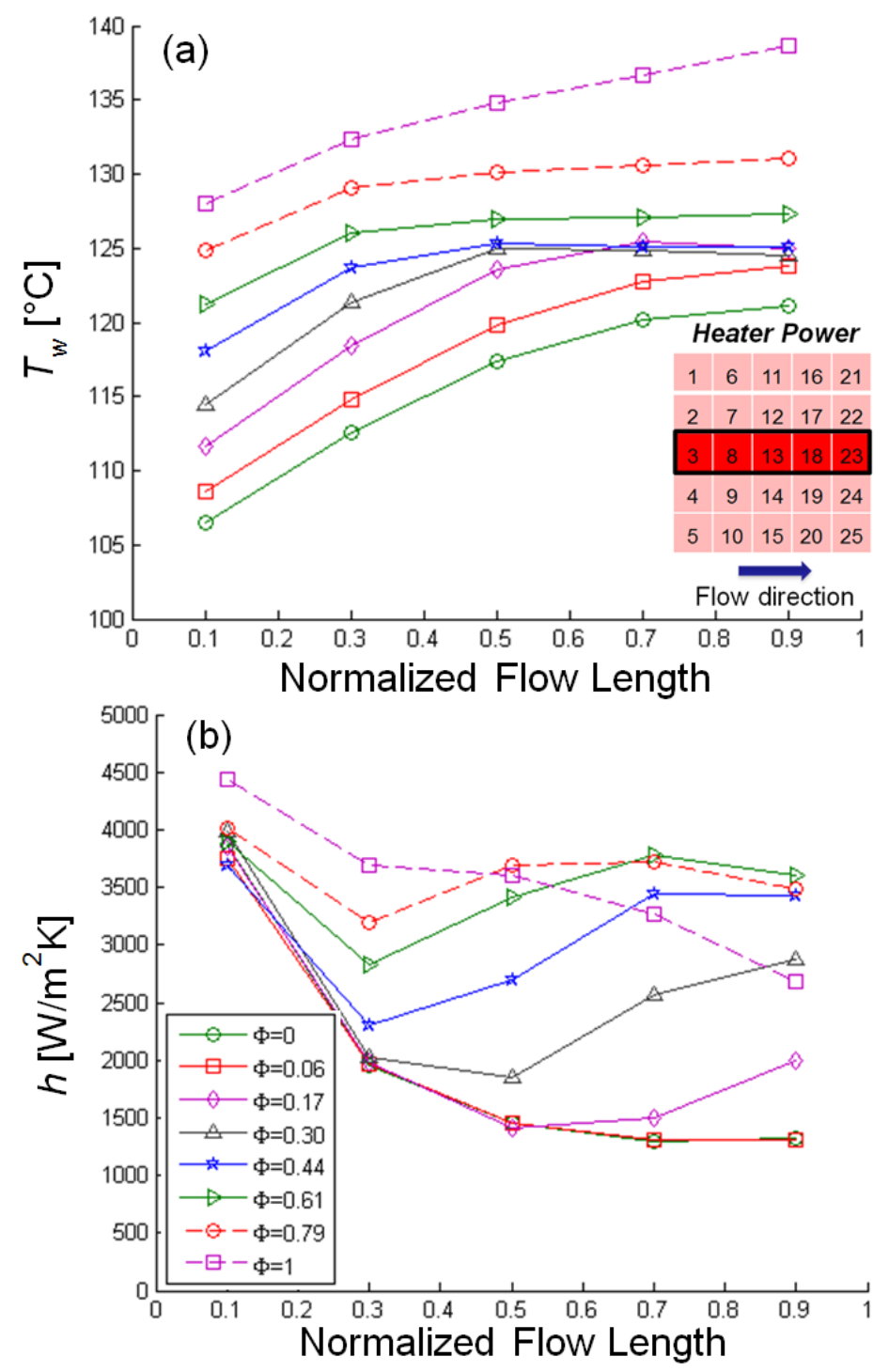

Figure 14. (a) Local wall temperature, and (b) heat transfer coefficient over the flow length at increasing degrees of nonuniformity between the heat flux at the peak and background heater locations for Case $2 \mathrm{~b}$. 


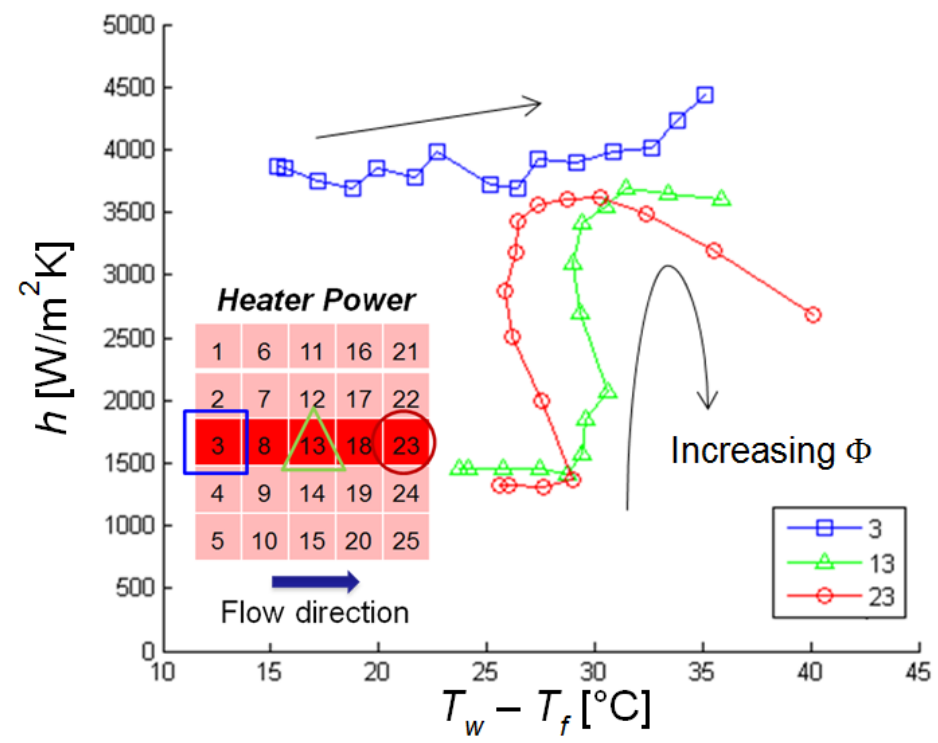

Figure 15. The heat transfer coefficient plotted against the wall excess temperature for sensors 3,13 , and 23 for Case $2 b$. 


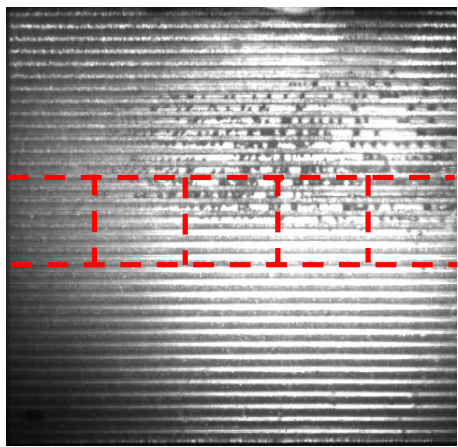

$\Phi=0.01$

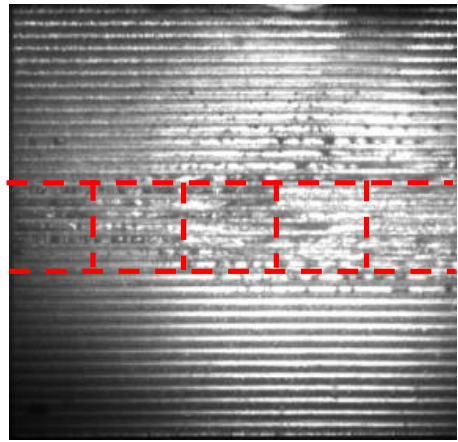

$\Phi=0.61$

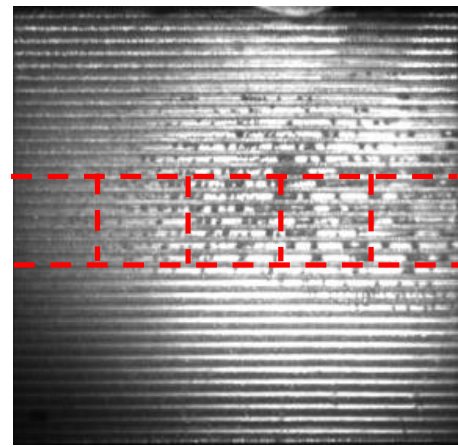

$\Phi=0.23$

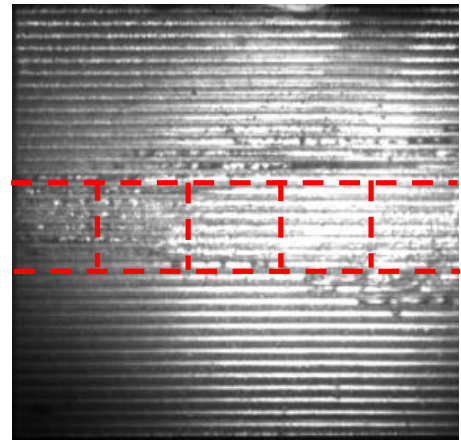

$\Phi=1.0$

Figure 16. Images at increasing $\boldsymbol{\Phi}$ values for a central streamwise peak extracted from high-speed video (Supplementary Video 6). Red lines indicate the locations of the peak-heated sensors. 